\title{
小议门式刚架结构工程常见质量问题及预防措施
}

张晓旭

盘锦红海实业集团有限公司

DOI:10.32629/btr.v1i5.1638

[摘要] 门式刚架结构在我国应用十分广泛,但是在工程建设的过程中也容易出现质量问题,造成较大的财产损失,影响工程 性能,因此我们必须正确认识门式刚架结构工程中常见的问题,并采取有效的预防措施保证工程建设的质量。

[关键词]门式刚架结构工程; 预防措施; 建设质量

门式刚架结构具有施工周期短、抗震性强和成本低等诸 多的优势, 所以其在工程建设中也得到了较为广泛的应用。 又因为门式刚架结构厂房建设的环节较多, 且影响因素也较 为繁杂, 所以工程质量问题屡见不鲜, 为了保证工程建设的 质量, 我们有必要积极采取有效的预防控制措施。

\section{1 门式刚架结构施工要点分析}

1.1 基础施工

基础施工是为了保证建筑物的自重, 并让上部荷载能够 充分且均匀地传给地基。门式刚架轻型房屋钢结构的基础深 度一般不超过 $5 \mathrm{~m}$, 基础施工中首先应按照要求开挖基坑, 同 时还要对开挖后的基坑进行严格的质量检查, 检查的内容有 基坑的位置、尺寸、标高、地基承载力等。在地基局部处理 的过程中, 需结合现场的具体情况, 在基础施工前, 严格检查 并验收基础垫层, 并在垫层上标注出结构轴线的具体位置, 加强基础混凝土钢筋放置的准确性和科学性。另外注意确保 基础混凝土和钢筋放置准确无误, 基础针栓与基础钢筋混凝 土连接应满足工程要求, 同时还要注意针固位置不能发生严 重的偏差。

再者, 基础混凝土浇筑过程中, 需让基础针栓的尺寸及 位置满足施工的基本要求, 避免针栓发生移位的现象, 且在 混凝土浇筑施工结束后, 按照要求完成浇水养护处理, 使整 体结构能够满足设计的基本要求, 之后方可进行上部结构的 安装施工。

\section{2 钢结构安装施工 \\ 1.2. 1 拼装}

在拼接施工中, 要在地面沿着梁长的方向每隔 $2-3 \mathrm{~m}$ 垫 1-2 根枕木, 同时还要及时核对梁号, 按照编号拼接结构。在 拼装施工中, 首先将各支点调整到水平的状态, 检查构件的 质量和性能, 若发现污染物应及时清除, 若发现变形情况, 要 及时调整。拼接后的构件需正确地摆放在枕木上, 从而避免 枕木发生变形的问题。在吊装前, 应对拼接好的构件进行复 核, 增强其紧固性。在拼装中, 可使用吊车沿其单片钢梁放置 在枕木上, 对枕木进行科学的调整, 使其保持平衡状态, 然后 再将其与另外一梠梁拼装在一起, 拧紧高强螺栓。

\subsection{2 吊装}

在吊装施工中, 应用吊索完成钢筋捆扎, 并将钢索与钢
梁分隔, 分隔时一般采用废轮胎, 以此防止钢梁和钢索发生 直接接触, 对钢梁造成严重的损坏。之后再缓慢提升, 支起钢 架, 检查梁的平衡情况。另外, 还要在大梁的两侧系上长绳, 让施工人员更好地控制梁的平衡。将梁扶正之后, 再缓慢提 升梁结构, 使梁离开地面, 停稳之后检查梁是否发生变形。确 定吊点位置没有误差后, 方可起吊。

此外, 还要在梁的两端各派一人, 携带插钎、螺栓等候, 在梁与柱顶的距离为 $30 \mathrm{c}$ 时, 柱顶的工作人员使用插钎将其 插入螺栓孔, 从而校正梁柱孔位。就位后按照要求上好螺栓。 在吊第一榀梁, 与吊车松钩之前, 可在梁的两侧设置 2 条缆 绳, 保证梁的平衡性。完成第二榀梁吊装施工后, 及时安装支 撑和屋面檩条, 在上述工作全部结束后方可松钩, 剩余的工 作也依此完成。

第一榀梁安装施工中, 松钩之前需对梁进行校正处理, 对准钢梁基座的中心线和定位轴线, 同时还要调整钢梁的垂 直度, 使其满足施工要求。第二榀钢梁吊装就为后, 不可立即 松钩, 应用棚槁临时固定, 接下来应完成支撑系统和部分檩 条的安装工作, 最后对结构进行校正和固定处理, 自第三榀 开始, 要在钢梁脊点与上线中点安装檩条, 从而达到校正和 固定钢梁的目的。

\section{2 .3 构件的连接和固定}

不同构件的连接接头都应经过十分严格的检查, 合格后 才能应用于施工中, 在焊缝安装和定位的过程中, 应仔细计 算点焊的数量、高度及长度, 不需要承受荷载的部分, 规定其 点焊的长度在设施焊缝长度的 $10 \%$ 以上, 不得小于 $50 \mathrm{~mm}$ 。

在焊缝安装施工中, 既要对外观进行全面的检查, 还要 检查其内部的质量及性能。对于安装施工中使用的临时螺栓, 其节点穿入的数量需经过准确计算, 且保证每个节点至少使 用两个螺栓。若应用在永久性焊接中, 且有少量错孔现象时, 可以用扩孔的方式来处理, 但是在施工中需注意扩孔数量不 得超过螺栓数量的 $30 \%$ 。若作为永久螺栓, 则在螺母下放置 垫圈, 如表面平整度不达标, 则需采用斜垫圈。螺母的固定应 严格按照设计的规定和要求来处理, 一般采用防松置或弹簧 垫圈, 粗制螺栓可打毛螺纹。而且规定永久性的普通螺栓放 置的垫圈在 2 个以内, 也可采用大螺母来替代垫圈。将螺栓 拧紧之后, 规定外露的螺丝在 2-3 扣之间, 并注意螺母的紧 
固性。

\section{3 墙面压型彩板安装施工}

墙面压型彩板安装施工中, 应以领条的位置为参考, 从 一段开始, 注意板间的紧密性, 之后再用螺钉固定板材。另外, 在施工中还要采取有效措施提高墙板接缝处的防水质量。压 型钢板安装施工中, 铺设和调整应同时进行, 待满足施工要 求后再实施固定处理。

1.4 屋面压型彩板安装施工

屋面压型钢板固定, 横波每两块板之间有一波搭接, 搭 接面主要采用密胶条进行密封处理, 之后使用防水密封膏密 封, 同时使用自攻螺钉和檩条予以固定, 每块板的端部应至 少设置 3 个螺钉, 若中间支撑的位置超过了 3 个檩距, 应至少 设置一个螺钉。在板材搭接在檩条上时, 需确保搭接的长度 能够满足工程设计的基本要求。搭接部分采用拉铆钉连接, 注意其防水的效果。这里要求外露的钉头涂抹密封膏, 包边 的钢板搭接选择背风向, 搭接的长度在 $20-50 \mathrm{~mm}$, 拉铆钉的间 距不超过 $500 \mathrm{~mm}$, 在防水处理时, 自攻钉拉铆钉要设置在波峰 上。

\section{2 门式刚架结构工程常见质量问题及预防措施}

2.1 选材阶段出现的质量问题和防控措施

结构中, 钢板主要有开平板和原平板, 开平板成本较低, 但是内应力较大, 而元拼版的价格较高, 但内应力较小, 且原 平板在切割时不会发生严重变形。一些企业为了降低成本, 一味选择开平板, 因此门式刚架结构在受到较大荷载时, 极 易出现变形问题。

门式刚架结构主要采用大六角头高强螺栓, 这种螺栓利 用梁段端板及梁柱结合端板上所产生的摩擦力, 来抵御截面 位置的剪力和弯矩。在从前的安全事故中发现, 门式刚架结 构通常采用普通螺栓, 螺栓的性能无法满足设计的要求, 在 承受较大力矩时会出现断裂。

针对以上问题, 应科学选择建筑材料, 并对入场材料进 行严格的检查, 保证正钢板和型钢满足工程建设的要求, 严 格检查厂家出具的质量检验证书和合格证书, 且高强螺栓应 在投入使用前, 进行严格的扭矩系数测试, 使其偏差在合理 范围内。

\section{2 施工阶段的质量问题及防范措施 \\ 2.2.1 焊接质量不达标}

痕接的质量直接影响结构的整体质量, 门式刚架结构中 的重要构件主要采用 $\mathrm{H}$ 型钢焊, 采用钢板平接焊缝以及角焊 缝的处理方式。角焊缝通常为二级焊缝, 钢板平接焊缝多为 一级焊缝, 焊接后应严格检测。焊接质量不佳是施工中的常 见问题, 这一问题会使结构产生残余应力。对此, 在焊接时,
要严格按照标准操作, 仔细检查内部是否存在缺陷, 如发现 问题应及时处理。

\subsection{2 喷装质量不佳}

喷装主要由表面处理和涂漆构成, 除锈的过程中, 主要 采用抛丸机和除锈等级为 Sa2. 5 的抛丸, 但是由于其成本较 高, 多数企业不采用这种除锈方式, 进而影响了除锈的效果。 喷漆时要求室内为 $125 \mathrm{um}$, 室外为 $150 \mathrm{um}$, 且喷刷两道环氧富 锌底漆, 同时还要在中间层喷刷一道环氧云铁漆, 两道面漆。 而一些厂家由于没有选择规定的油漆, 因而影响了喷漆的质 量。

\subsection{3 地脚螺栓安装不合理}

门式刚架结构基础和地脚螺栓定位的要求较高, 柱地脚 螺栓的标高和定位对结构的稳定性有着十分显著的影响, 在 一些有质量缺陷的结构当中, 地脚螺栓标高定位不准, 导致 受力受到了较大的影响, 部分柱结构底板螺栓孔下并没有设 置垫板, 刚柱从柱底脱落, 进而使刚架柱发生倾斜。对此, 应 按照施工图中的螺栓来制作模子, 完成预制工作, 然后还要 用定位模固定螺栓, 应用钢筋框焊接, 且预埋前需预制两块 定位模板。预埋时还应将螺栓套到模板当中, 并用螺母固定, 严格控制露出的长度和模板的标高和轴线, 在调整后再固定 基础筋。

2.2. 4 围护结构安装不科学

在维护结构安装中, 主要分为面板安装以及采光板安装 两个部分, 在面板安装的过程中, 可在已经安装完的面板上 拖拽正在安装的板材, 从而造成涂层脱落的现象; 采光板搭 接的过程中, 由于采光板的厚度与彩板的咬合效果较差, 故 而容易出现漏雨的问题。该结构主要应用钢板作为维护结构, 施工细节控制的水平对施工效果有着较大的影响, 因此在工 程施工中应与设计要求保持高度一致, 从而确保其外观及功 能。

\section{3 结语}

门式刚架结构施工是一项较为复杂的工作, 基于此, 我 们必须正确处理工程中常见的质量缺陷, 进而有效提高工程 的建设质量, 避免工程出现严重的安全事故, 最终让工程顺 利竣工。

\section{[参考文献]}

[1]刘春雨.门式刚架结构工程常见质量问题及预防措 施分析[J].江西建材,2016,(11):70.

[2]高娟.轻型门式刚架结构在装配式住宅中的实用性分 析[J].科学技术创新,2018,(09):115-116.

[3]邹沁.轻型门式刚架设计应注意的几个问题 [J].科技 与企业,2015,(08):113. 